\title{
Hexose absorption from jejunal loops in situ in zinc-deficient and Zn-supplemented rats
}

\author{
BY SUSAN SOUTHON, JENNIFER M. GEE AND I. T. JOHNSON \\ AFRC Food Research Institute Norwich, Colney Lane, Norwich NR4 7UA
}

(Received 22 April 1985 - Accepted 14 August 1985)

\begin{abstract}
1. Immature, male Wistar rats were given a low-zinc semi-synthetic diet $(2 \mathrm{mg} \mathrm{Zn} / \mathrm{kg}$ ) for $22-28 \mathrm{~d}$. Control groups received a similar diet supplemented with $58 \mathrm{mg} \mathrm{Zn} / \mathrm{kg}$ either ad lib., or in amounts matched to the consumption of the $\mathrm{Zn}$-deficient group. There was a rapid onset of reduced food consumption and growth retardation in the $\mathrm{Zn}$-depleted animals.

2. Serosal surface area of small intestines taken from $\mathrm{Zn}$-deficient rats was significantly reduced compared with that of control animals. Villi, dissected from samples of proximal jejunum, were markedly smaller than those of control rats and were present in greater numbers per unit area of serosa.

3. Luminal loss of galactose from jejunal loops in situ was significantly greater in the Zn-deficient rats compared with controls when expressed in terms of unit dry weight of intestine and serosal or villous surface area. Since only a small proportion of the total galactose remained in the mucosal tissue and associated extracellular space, this loss could only be accounted for by an increased efficiency of net trans-epithelial transport. Differences in total galactose absorption per unit length of jejunum were not so marked.

4. This intestinal adaptation to $\mathrm{Zn}$-deficiency allows the maintenance of normal, and possibly increased, rates of hexose transfer into the body of animals exhibiting severe growth retardation, reduced food utilization and abnormal glucose metabolism.
\end{abstract}

Previous transport studies in vitro showed that there is a marked enhancement of carrier-mediated galactose and 3-O-methyl glucose uptake into mucosal tissue of zincdepleted rats compared with feed-restricted and ad lib.-fed controls (Southon et al. 1984). Kinetic analysis of the results demonstrated that this was due to an increase in the maximum transport rate rather than carrier affinity, indicating that larger numbers of carrier sites are present per unit dry weight of small intestine. This finding has important implications since $\mathrm{Zn}$-deficiency has been reported to result in a reduction in both the secretion of and sensitivity to insulin (Quarterman et al. 1966) and abnormal glucose metabolism (Reeves \& O'Dell, 1983). There are several reports of reduced glucose tolerance in $\mathrm{Zn}$-deficient rats given glucose intraperitoneally; however, this effect was not observed when the dose was given orally (Quarterman et al. 1966; Hendricks \& Mahoney, 1972). It has been suggested that the normal glucose tolerance curves following an oral dose of glucose could be attributed to poor absorption of nutrients from the gut of $\mathrm{Zn}$-deficient animals (Hove et al. 1937), or to an increased stimulation of insulin secretion (Hendricks \& Mahoney, 1972). Our findings clearly do not support the first of these hypotheses.

An increased capacity to transport substrate across the brush-border membrane does not necessarily imply an increased rate of trans-epithelial intestinal transport. In the present study we investigated the absorption of galactose from intestinal loops in situ in anaesthetized $\mathrm{Zn}$-depleted and control rats. This technique allows studies to be performed on the living animal using lengths of intestine with intact blood supply, thus mimicking the in vivo situation more closely. In addition, luminal loss, intestinal tissue accumulation, and transfer of the radiolabelled hexose into the bloodstream can be measured. 


\section{MATERIALS AND METHODS}

\section{Animals and diets}

Thirty-six immature, male Wistar rats (approximately $100 \mathrm{~g}$ ) were randomly divided into three groups and housed in polypropylene cages with stainless-steel-gridded bottoms and tops. Rats were caged in pairs to eliminate the stress of isolation. The $\mathrm{Zn}$-deficient group received a semi-synthetic diet containing $2 \mathrm{mg} \mathrm{Zn/kg}$ diet ad lib. The second and third groups received a similar diet supplemented with $58 \mathrm{mg} \mathrm{Zn} / \mathrm{kg}$ diet. The first of these control groups was given an amount of food equal to that consumed on the previous day by a matched pair of $\mathrm{Zn}$-deficient rats. This group was designated the feed-restricted group. The third group was fed ad lib. The composition of the semi-synthetic diet was similar to that previously described (Southon et al. 1984) with the addition of $5 \mathrm{~g}$ methionine $/ \mathrm{kg}$ diet. All rats received distilled water $a d$ lib. Food intakes were measured daily and body-weights recorded at twice weekly intervals. The body-weight gain of cage mates was compared at each weighing as an index of the relative amounts of food consumed by each individual. On days 22,23 and 28 of the study, equal numbers of rats from each group were taken for transport studies, followed by morphological examination of the jejunum.

\section{Transport study}

On the day before they were killed, feed-restricted control rats consumed their daily ration of food between 16.00 and 17.00 hours. All animals were then fasted overnight and transport studies performed between 10.00 and 12.00 hours on the following day. Animals were anaesthetized by intraperitoneal injection of sodium barbiturate (Sagatal: May \& Baker, Dagenham, Essex; $1 \mathrm{ml} / \mathrm{kg}$ body-weight), placed on a heated operating table at $37^{\circ}$ and the abdomen opened. The small intestine was ligatured $100 \mathrm{~mm}$ from the pyloric sphincter and a further ligature was positioned $50 \mathrm{~mm}$ distally along the jejunum. The isolated loop was filled with $40 \mathrm{~mm}$-galactose in Krebs bicarbonate ringer buffer containing $\left[{ }^{3} \mathrm{H}\right]$ galactose $(1.0 \mu \mathrm{Ci} / \mathrm{ml})$ and ${ }^{14} \mathrm{C}$-labelled polyethylene glycol (PEG; molecular weight 4000 ; $0.5 \mu \mathrm{Ci} / \mathrm{ml}$ ), and replaced in the abdomen. After $8 \mathrm{~min}$ the isolated loop was removed intact, with approximately $10 \mathrm{~mm}$ of additional jejunum, which was removed to fixative for morphological examination. The loop was rinsed, trimmed free of mesentery and fat, blotted lightly and weighed on a torsion balance. The loop was then cut open and the lumenal contents collected. The loop was reweighed, placed in a preweighed vial and dried at $85^{\circ}$ for $18 \mathrm{~h}$. Blood was collected by cardiac puncture and placed in a heparinized vial.

Dried tissue samples were digested in concentrated nitric acid $\left(0.4 \mathrm{ml} ; 70^{\circ}\right.$ for $\left.15 \mathrm{~min}\right)$ in tightly capped vials, cooled and mixed with Trizma base $(3.6 \mathrm{ml} ; 0.75 \mathrm{M})$. Portions $(0.5 \mathrm{ml})$ were diluted to $2.0 \mathrm{ml}$ with distilled water and added to $18 \mathrm{ml}$ scintillation mixture (Cocktail T Scintran; BDH, Poole, Dorset). Preliminary experiments in which samples of intestine were either acid-digested and counted, or combusted and counted, showed no loss of ${ }^{3} \mathrm{H}$ or ${ }^{14} \mathrm{C}$ during acid digestion. Lumenal contents were made up to $2 \cdot 0 \mathrm{ml}$ with distilled water and added to $18 \mathrm{ml}$ scintillant. Whole blood samples $(0.2 \mathrm{ml})$ were digested at room temperature in $1.5 \mathrm{ml}$ Soluene-350 (Packard, Reading, Berks)-propan-2-ol (1:1, v/v). After $48 \mathrm{~h}$ the samples were decolorized by the addition of $0.5 \mathrm{ml} \mathrm{hydrogen} \mathrm{peroxide}(300-350 \mathrm{ml} / \mathrm{l})$ and counted in $18 \mathrm{ml} 0.5 \mathrm{M}$-hydrochloric acid-insta-gel (Packard) $(1: 9, \mathrm{v} / \mathrm{v})$ after dark adaptation.

Prepared tissue and fluid samples were counted in polythene vials using a Philips PW 4700 liquid-scintillation spectrometer and a dual-label counting programme without automatic quench compensation. Counting efficiency was measured by external standard channels ratio.

Mucosal extracellular space and fluid transport were calculated on the basis of the amount 
of the non-transported ${ }^{14} \mathrm{C}$-labelled PEG associated with the tissue, and the change in the lumenal concentration of ${ }^{14} \mathrm{C}$-labelled PEG respectively. Hexose transfer into the bloodstream was calculated by correcting the change in lumenal $\left[{ }^{3} \mathrm{H}\right]$ galactose concentration for mucosal accumulation of the radiolabel.

\section{Morphological study}

Samples of jejunum, obtained from animals in the transport study, were fixed by immersion in a mixture of absolute ethanol and glacial acetic $(75: 25, \mathrm{v} / \mathrm{v})$ for $24 \mathrm{~h}$, followed by storage in ethanol-water $(75: 25, \mathrm{v} / \mathrm{v})$. Subsequently, each sample was slit open and measured under a dissecting microscope, fitted with a graduated eyepiece, to obtain an estimate of the width across the serosal surface and the number of villi per unit area of serosal surface. A total of ten villi were then removed from each sample of jejunum by microdissection with sharpened needles. Estimates of the maximum height, basal width and thickness were made using the graduated eyepiece. From the individual villous surface area and the density of the villous population, it was possible to estimate the villous surface per unit area of serosa (VSA) as follows:

$$
\text { VSA }=n\left(w h+2 t h^{\prime}\right),
$$

where $n$ is the number of villi per unit area of serosa, $w$ is the basal width, $h$ is the maximum height, $t$ is the thickness and $h^{\prime}$ is the length of the edge from base to tip of individual villi. This formula is based on the assumption that villous shape in the proximal jejunum conforms roughly to that of a wedge, with absorbing surfaces on four sides.

\section{Statistics}

The significance of differences between means for the $\mathrm{Zn}$-deficient group and the feedrestricted control group was estimated using Student's paired $t$ test, comparing average values for each cage of rats. All other comparisons were made using Student's unpaired $t$ test.

\section{RESULTS}

The mean values for body-weight gain and food intake over the first $21 \mathrm{~d}$ feeding period are shown in Table 1 . Rats given a low-Zn diet consumed on average $44 \%$ less food over this period than the ad lib.-fed control rats. The growth rate, as judged by body-weight gain, of the feed-restricted controls was significantly greater than that of the $\mathrm{Zn}$-deficient group. Comparisons of individual rates of body-weight gain showed that growth rates of cage mates within each group were similar, indicating that there were no large variations in food intake between rats housed together. The $\mathrm{Zn}$-deficient rats exhibited the characteristic symptoms of the deficiency over the experimental period, including erratic patterns of feeding, hair loss, skin lesions and lethargy.

\section{Morphological study}

There was a significant reduction in the circumference of small intestines from $\mathrm{Zn}$-deficient animals compared with both groups of controls, which resulted in a $15-20 \%$ decrease in serosal surface area per unit length of jejunum (Table 2). Villi dissected from samples of proximal jejunum of $\mathrm{Zn}$-depleted rats were significantly shorter, narrower and consequently of smaller surface area than those from control animals. However, they were present in larger numbers per unit area of serosa, with the result that the villous surface per unit area of serosa was not significantly different from that of the controls (Table 2). Villous density in the jejunum of feed-restricted rats was also significantly greater than in the ad lib.-fed controls but the increase was not as marked as in the $\mathrm{Zn}$-deficient animals. 
Table 1. Body-weight gain and food intake over the first $21 \mathrm{~d}$ of the study for zinc-deficient, feed-restricted and ad lib.-fed control rats*

(Values are means with their standard errors for twelve rats)

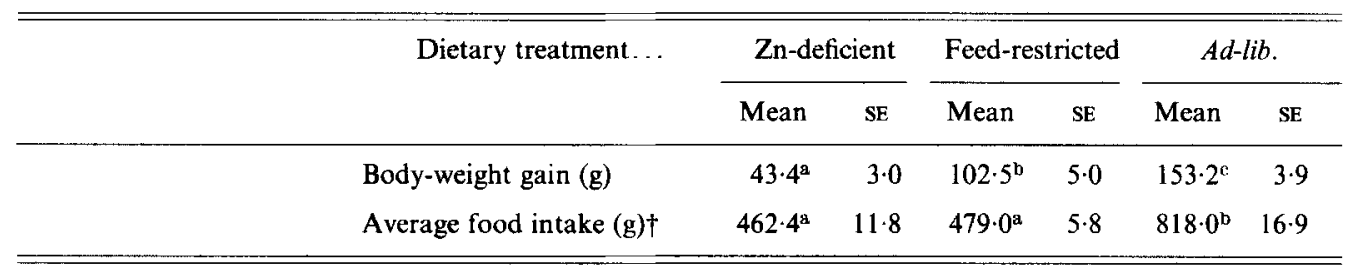

a,b,c Mean values with different superscript letters were significantly different $(P<0.05)$.

* For details of dietary treatments, see p. 194.

$\dagger$ Average intake of six pairs of rats.

Table 2. Morphology of jejunum and microdissected villi from zinc-deficient, feed-restricted and ad lib.-fed control rats*

(Values are means with their standard errors for twelve rats)

\begin{tabular}{|c|c|c|c|c|c|c|}
\hline \multirow[t]{2}{*}{ Dietary treatment... } & \multicolumn{2}{|c|}{ Zn-deficient } & \multicolumn{2}{|c|}{ Feed-restricted } & \multicolumn{2}{|c|}{ Ad-lib. } \\
\hline & Mean & SE & Mean & SE & Mean & SE \\
\hline \multicolumn{7}{|l|}{ Jejunal loop } \\
\hline Circumference (mm) & $7 \cdot 7^{a}$ & $0 \cdot 2$ & $9 \cdot 0^{\mathrm{b}}$ & $0 \cdot 2$ & $9 \cdot 5^{\mathrm{b}}$ & 0.4 \\
\hline Serosal surface area $\dagger\left(\mathrm{cm}^{2} / 5 \mathrm{~cm}\right)$ & $3 \cdot 85^{a}$ & $0 \cdot 1$ & $4 \cdot 5^{b}$ & $0 \cdot 1$ & $4 \cdot 75^{b}$ & $0 \cdot 2$ \\
\hline \multicolumn{7}{|l|}{ Villi } \\
\hline Height $(\mu \mathrm{m})$ & $500^{\mathfrak{a}}$ & 10 & $570^{\mathrm{b}}$ & 20 & $560^{\mathrm{b}}$ & 10 \\
\hline Width $(\mu \mathrm{m})$ & $440^{\mathrm{a}}$ & 20 & $520^{\mathrm{b}}$ & 30 & $580^{\mathrm{b}}$ & 30 \\
\hline Thickness $(\mu \mathrm{m})$ & $63^{\mathfrak{a}}$ & 4 & $75^{\mathrm{b}}$ & 4 & $76^{\mathrm{b}}$ & 3 \\
\hline Density (no. $/ \mathrm{cm}^{2}$ ) & $2010^{\mathrm{a}}$ & 60 & $1820^{\mathrm{b}}$ & 40 & $1550^{\mathrm{c}}$ & 60 \\
\hline Surface area per villus $\left(\mathrm{mm}^{2}\right)$ & $0 \cdot 29^{a}$ & 0.02 & $0 \cdot 39^{\mathrm{b}}$ & 0.03 & $0.42^{\mathrm{b}}$ & 0.02 \\
\hline $\begin{array}{l}\text { Villous surface area per unit area } \\
\text { serosa }\left(\mathrm{mm}^{2} / \mathrm{mm}^{2}\right)\end{array}$ & $5 \cdot 8^{a}$ & $0 \cdot 3$ & $7 \cdot 1^{\mathrm{a}}$ & 0.4 & $6 \cdot 5^{a}$ & 0.3 \\
\hline
\end{tabular}

a, b, c Mean values with different superscript letters were significantly different $(P<0.05)$.

* For details of dietary treatments, see p. 194.

$\dagger$ Surface area per loop.

\section{Transport study}

Data for one pair of rats per group was not available for the transport study due to death of animals whilst under anaesthetic, or loss of lumenal contents. Observations were therefore restricted to five pairs of rats per group.

Animals maintained on a low- $\mathrm{Zn}$ diet showed a significant increase in the rate of lumenal loss of galactose per unit dry weight, serosal surface and villous surface of jejunum compared with control rats. This was accompanied by an increase in the concentration of the radiolabel in the blood (Table 3). The concentration of galactose in the intestinal tissue and associated extracellular space of the $\mathrm{Zn}$-depleted rats was, however, no higher than in tissue from control animals. Differences in the total amount of galactose transported from the jejunal loop during the incubation period were not so marked. Nevertheless, the rate of galactose absorption per unit length of jejunum in the $\mathrm{Zn}$-depleted rats was significantly 
Table 3. Lumenal loss, mucosal accumulation and net transport of galactose over 8 min from jejunal loops in zinc-deficient, feed-restricted and ad lib.-fed control rats*

(Values are means with their standard errors for tem rats)

\begin{tabular}{|c|c|c|c|c|c|c|}
\hline \multirow[t]{2}{*}{ Dietary treatment... } & \multicolumn{2}{|c|}{ Zn-deficient } & \multicolumn{2}{|c|}{ Feed-restricted } & \multicolumn{2}{|c|}{ Ad-lib. } \\
\hline & Mean & SE & Mean & SE & Mean & SE \\
\hline $\begin{array}{l}\text { Lumenal loss ( } \mu \text { mol galactose } / \mathrm{cm}^{2} \\
\text { villous surface area) }\end{array}$ & $0 \cdot 55^{\mathrm{a}}$ & 0.05 & $0 \cdot 37^{\mathrm{b}}$ & 0.02 & $0 \cdot 37^{\mathrm{b}}$ & 0.04 \\
\hline $\begin{array}{l}\text { Mucosal accumulation ( } \mu \mathrm{mol} \text { galactose } / \mathrm{cm}^{2} \\
\text { villous surface area) }\end{array}$ & $20 \cdot 01^{a, b}$ & 0.003 & $0 \cdot 02^{\mathrm{a}}$ & 0.003 & $0.01^{\mathbf{b}}$ & 0.002 \\
\hline $\begin{array}{l}\text { Net transport } \dagger \mu \mathrm{mol} \text { galactose } / \mathrm{cm}^{2} \\
\text { villous surface area }\end{array}$ & $0 \cdot 52^{z}$ & $0 \cdot 04$ & $0 \cdot 34^{\mathrm{b}}$ & 0.02 & $0 \cdot 34^{\mathrm{b}}$ & 0.03 \\
\hline$\mu \mathrm{mol}$ galactose/g dry weight jejunum & $163^{\mathrm{a}}$ & 7 & $123^{\mathrm{b}}$ & 7 & $108^{\mathrm{b}}$ & 6 \\
\hline$\mu \mathrm{mol}$ galactose $/ \mathrm{mm}$ length jejunum & $0 \cdot 224^{a}$ & 0.01 & $0.213^{\mathrm{a}, \mathrm{b}}$ & 0.01 & $0 \cdot 185^{b}$ & 0.01 \\
\hline $\begin{array}{l}\text { Blood concentration ( } \mu \mathrm{mol} \text { galactose } / \mathrm{ml} \\
\text { whole blood) }\end{array}$ & $0 \cdot 15^{\mathrm{a}}$ & 0.02 & $0 \cdot 1^{\mathrm{b}}$ & 0.01 & $0 \cdot 09^{b}$ & $0 \cdot 01$ \\
\hline
\end{tabular}

a, b Mean values with different superscript letters were significantly different $(P<0.05)$.

* For details of dietary treatment, see p. 194.

$\dagger$ Lumenal loss corrected for accumulation of $\left[{ }^{3} \mathrm{H}\right]$ galactose in mucosal tissue and extracellular space.

Table 4. Net transport of water over 8 min from jejunal loops in zinc-deficient, feed-restricted and ad lib.-fed control rats*

(Values are means with their standard errors for ten rats)

\begin{tabular}{|c|c|c|c|c|c|c|}
\hline \multirow[t]{2}{*}{ Dietary treatment... } & \multicolumn{2}{|c|}{ Zn-deficient } & \multicolumn{2}{|c|}{ Feed-restricted } & \multicolumn{2}{|c|}{$A d-l i b$} \\
\hline & Mean & SE & Mean & SE & Mean & SE \\
\hline$\mu 1 / \mathrm{g}$ dry weight & $1485^{a}$ & 170 & $965^{b}$ & 140 & $788^{\mathrm{b}}$ & 90 \\
\hline$\mu \mathrm{l} / \mathrm{cm}^{2}$ villous surface & $4 \cdot 85^{a}$ & 0.6 & $2 \cdot 90^{\mathrm{b}}$ & 0.4 & $2 \cdot 48^{b}$ & $0 \cdot 3$ \\
\hline$\mu 1 / \mathrm{mm}$ length of jejunum & $2 \cdot 28^{\mathrm{a}}$ & $0 \cdot 23$ & $1 \cdot 84^{b}$ & 0.20 & $1 \cdot 49^{b}$ & $0 \cdot 17$ \\
\hline
\end{tabular}

a. b Mean values :vith different superseript letters were significantly different $(P<0.05)$.

* For details of aietary treatments, see p. 194.

greater than the value for the ad lib.-fed controls (Table 3). Net fluid transport was consistently higher in $\mathrm{Zn}$-depleted animals compared with both control groups, irrespective of the basis of expressing the values (Table 4).

\section{DISCUSSION}

In a previous study we investigated the phloridzin-sensitive uptake of galactose and 3-O-methyl glucose in vitro by everted jejunal rings from $\mathrm{Zn}$-deficient and $\mathrm{Zn}$-supplemented rats. The study demonstrated that $\mathrm{Zn}$-deficiency was accompanied by a marked enhancement of carrier-mediated hexose uptake in the jejunal mucosa, which appeared to result from the presence of larger numbers of carrier sites per unit dry weight of intestine (Southon $e t$ 
al. 1984). This increased capacity to transport substrate across the brush-border membrane however does not necessarily imply an increased rate of net trans-epithelial transport. In the present study, galactose loss from jejunal loops in situ in anaesthetized rats was investigated, in order to provide direct evidence of an alteration in the rate of hexose absorption in animals consuming a low-Zn diet. This investigation clearly showed that the rate of lumenal loss of galactose per unit dry weight and per unit surface area of jejunum was significantly increased in dietary $\mathrm{Zn}$-depletion. Since galactose is poorly metabolized by the mucosal tissue, and the concentration of the radiolabelled galactose in the mucosa and associated extracellular space of $\mathrm{Zn}$-depleted rats was no higher than in controls, this increased loss from the lumen could only be accounted for by an accelerated transfer of the substrate into the bloodstream.

Morphological studies confirm that $\mathrm{Zn}$-deficiency in the rat is accompanied by a reduction in villous dimensions and an increase in the number of villi present per unit serosal surface area of jejunum. In contrast to our previous findings, villous density was also significantly greater in the feed-restricted controls, but this increase was not as marked as in the $\mathrm{Zn}$-deficient animals. We suggest that this increase is an adaptive response allowing the maintenance of intestinal absorptive surface during prolonged periods of restricted nutrient intake. It has been argued that an increase in villous surface, such as observed in alloxan-induced diabetic rats, is associated with hyperphagia and consequent increased lumenal nutrition (Lorenz-Meyer et al. 1977), but in this instance villous density remained unchanged. Alterations in mucosal morphology and cellular proliferation in the $\mathrm{Zn}$-deficient rat are discussed in detail elsewhere (Southon et al. 1984, 1985).

The alterations in intestinal structure resulting from inadequate dietary $\mathrm{Zn}$, coupled with the severe growth retardation characteristic of the deficiency, make changes in intestinal function difficult to interpret with respect to rates of nutrient uptake and utilization. No single index or method is satisfactory for characterizing intestinal absorption, particularly when groups of animals differ greatly in levels of food intake, body-weight and intestinal morphology (Levin, 1967). In the present study, although Zn-deficiency is associated with a considerable increase in the rate of galactose absorption when expressed in terms of dry weight or surface area of intestine, differences between $\mathrm{Zn}$-deficient and $\mathrm{Zn}$-supplemented rats are not so great when transport is expressed in terms of unit length. This occurs because dietary $\mathrm{Zn}$-depletion in the rat often results in a reduction in dimensions of the small intestine, which may account for the apparent disparity between our findings and those of other authors who report that animals maintained on a low-Zn diet exhibit similar or lower rates of lumenal loss of glucose in vivo compared with $\mathrm{Zn}$-supplemented controls (Reeves \& O'Dell, 1983; Ghishan, 1984). Such absorption studies performed at a single substrate concentration, and without reference to intestinal structural changes, do not lend themselves to investigations of absorption mechanisms at the cellular level. Our investigations, which include both kinetic and morphological studies, suggest that these mechanisms are altered in response to dietary $\mathrm{Zn}$-depletion (Southon et al. 1984). There also appeared to be some response to prolonged feed restriction in the control animals, in that rates of galactose transport per unit dry weight and per unit length of jejunum tended to be higher in this group of rats compared with ad lib.-fed controls. This agrees with earlier kinetic studies where we observed a significant increase in maximum transport rate in feed-restricted animals compared with ad lib.-fed controls (Southon et al. 1984).

Fluid absorption in the jejunum is generally regarded as a passive consequence of glucose-stimulated electrolyte movement. It may be expected, therefore, that an increased rate of hexose absorption would be accompanied by an increase in the net transport of sodium and hence water and, indeed, lumenal loss of water from jejunal loops of $\mathrm{Zn}$-deficient rats was significantly higher than that of controls irrespective of the basis of expressing the 
values. It is surprising that Ghishan (1984), in a single-pass perfusion study, observed net secretion of both $\mathrm{Na}$ and water, accompanied by net absorption of glucose, in $\mathrm{Zn}$-deficient rats. It should be noted, however, that the animals used by Ghishan (1984) suffered from diarrhoea, which is a feature we have never observed in uncomplicated $\mathrm{Zn}$-deficiency. The possibility exists therefore that the fluid secretion observed by Ghishan (1984) might reflect secondary bacterial infection.

Our findings suggest that $\mathrm{Zn}$-deficiency is associated with an intestinal adaptation which permits the maintenance of normal, and possibly increased, rates of galactose and glucose transport into the body despite a reduction in total absorptive surface. The implication of this adaptation in animals exhibiting lower body-weight, size and hence blood volume compared with $\mathrm{Zn}$-supplemented animals has yet to be determined. Measurements of radiolabelled galactose in whole blood at the end of the $8 \mathrm{~min}$ incubation period indicated that, although total hexose transfer into the body was only slightly greater in $\mathrm{Zn}$-depleted rats compared with controls, the concentration of galactose in the blood of $\mathrm{Zn}$-deficient rats was significantly higher. This may be a consequence of reduced blood volume in these animals, or the result of differences in galactose clearance from the blood. Investigations of the effect of dietary $\mathrm{Zn}$-depletion on glucose homeostasis have provided conflicting results. Hendricks \& Mahoney (1972) demonstrated that although glucose tolerance was impaired when rats were dosed intraperitoneally, this was not the case when the dose was administered orally. Boquist \& Lernmark (1969) and Brown et al. (1975) found no differences in serum insulin between $\mathrm{Zn}$-deficient and $\mathrm{Zn}$-supplemented animals, whereas the work of Quarterman et al. (1966), Quarterman \& Florence (1972) and Huber \& Gershoff (1973) suggests that there are decreased levels of circulating insulin in $\mathrm{Zn}$-deficient rats, coupled with a resistance to hypoglycaemic coma after insulin dosing. Both glucose homeostasis and metabolism are notoriously difficult to study in Zn-deficiency because of the effect of poor $\mathrm{Zn}$ nutrition on food intake, feeding patterns and growth. The findings of Reeves \& O'Dell (1983), however, provide evidence of alterations in glucose incorporation into adipose free fatty acids and liver glycogen in meal-fed $\mathrm{Zn}$-deficient rats compared with meal-fed feed-restricted controls, which suggests a regulatory role for $\mathrm{Zn}$ in carbohydrate metabolism.

The importance of the changes in intestinal structure and function described in the present paper, in relation to whole-body nutrient utilization, requires further investigation. In particular, both the magnitude and dynamics of insulin response, rates of glucose entry into tissues and glucose utilization by tissues in $\mathrm{Zn}$-depleted and feed-restricted animals with comparable patterns of food intake should be considered in more detail.

The authors thank Mrs J. Cooke and Mr P. Muddel for skilled animal care, and Miss J. Brown and Mrs Z. Piper for technical assistance.

\section{REFERENCES}

Boquist, L. \& Lernmark, A. (1969). Acta Pathologica et Microbiologica Scandinavica 6, 215-228.

Brown, E. D., Penhos, J. C., Recant, L. \& Smikthy, J. C. Jr (1975). Proceedings of the Society for Experimental Biology and Medicine 150, 557-560.

Ghishan, F. K. (1984). Journal of Pediatric Gastroenterology and Nutrition 3, 608-612.

Hendricks, D. G. \& Mahoney, A. W. (1972). Journal of Nutrition 102, 1079-1084.

Hove, E., Elvehjem, C. A. \& Hart, E. B. (1937). American Journal of Physiology 119, 768-775.

Huber, A. M. \& Gershoff, S. N. (1973). Journal of Nutrition 103, 1739-1744.

Levin, R. J. (1967). British Medical Bulletin 23, 209-212.

Lorenz-Meyer, H., Thiel, F., Menge, H., Gottesburen, H. \& Ricken, E. O. (1977). Research in Experimental Medicine 170, 89-99.

Quarterman, J. \& Florence, E. (1972). British Journal of Nutrition 28, 75-79. 
200 Susan Southon, Jennifer M. Gee and I. T. Johnson

Quarterman, J., Mills, C. F. \& Humphries, W. R. (1966). Biochemical and Biophysical Research Communications 25, 354-359.

Reeves, P. G. \& O'Dell, B. L. (1983). British Journal of Nutrition 49, 441-452.

Southon, S., Gee, J. M. \& Johnson, I. T. (1984). British Journal of Nutrition 52, 371-380.

Southon, S., Livesey, G., Gee, J. M. \& Johnson, I. T. (1985). British Journal of Nutrition 53, 595-603. 